\title{
Perspectivas em avaliação psicológica
}

\author{
Lariana Paula Pinto ${ }^{1}$ - Universidade São Francisco, Itatiba, Brasil
}

Santos, A. A. A., Sisto, F. F., Boruchovitch, E. \& Nascimento, E. (2010). Perspectivas em avaliação psicológica. São Paulo: Casa do Psicológo, 314 p.

A área da avaliação psicológica vem apresentando crescimento nos últimos anos, ampliando seus contextos e aplicações, além de contribuir para o desenvolvimento de pesquisas que acabam por fortalecer a psicologia. A partir disso, Acácia Aparecida Angeli dos Santos, Fermino Fernandes Sisto, Evely Boruchovitchi e Elizabeth do Nascimento organizaram este livro, no qual apresentam um panorama das temáticas e tendências atualmente investigadas na área de avaliação psicológica. A obra está organizada em treze capítulos, elaborados por especialistas na área, provenientes de diversas regiões do país.

O primeiro capítulo, sob autoria de Irai Cristina Boccato Alves, Patrícia Waltz Schelini, Elizabeth do Nascimento e Simone Ferreira da Silva Domingues, enfatiza a avaliação cognitiva infantil, fazendo um levantamento e uma descrição dos testes psicológicos voltados para esse fim. São apresentados os doze instrumentos aprovados para a utilização na avaliação intelectual infantil. As autoras, ao final, chamam a atenção para a predominância de testes construídos em outros países e adaptados para a realidade brasileira, bem como a escassez de instrumentos que avaliem crianças com idades inferiores a cinco anos e a limitação da representatividade da amostra, visto que a maioria das pesquisas realizadas concentram-se nos estados de São Paulo e Rio Grande do Sul.

O objetivo de Makilim Nunes Baptista, Fermino Fernandes Sisto, Ana Paula Noronha e Irani Argimon, no segundo capítulo, foi apresentar as contribuições da avaliação psicológica para o diagnóstico da depressão, que, por sua vez, vem sendo considerada como um dos transtornos de humor de maior prevalência na população mundial. Os autores destacam que quanto mais pesquisas forem desenvolvidas nessa temática, maiores são as chances de se construir um instrumento que represente melhor as características desse transtorno, fortalecendo a precisão de seu diagnóstico.

No terceiro capítulo, as autoras Eliane Ferreira Carvalho Banhato e Elizabeth do Nascimento objetivaram apresentar instrumentos utilizados na avaliação cognitiva de idosos, ressaltando que para melhor compreender esta etapa do desenvolvimento, faz-se necessário investigar as funções cognitivas, a fim de distinguir os aspectos benignos e os patológicos da

11E-mail: lari_paula@hotmail.com cognição. As autoras apresentam dificuldades e limitações para a avaliação dessa população, como por exemplo, a carência de instrumentos de avaliação cognitiva que contemplem o grupo etário acima de sessenta anos, detecção de comprometimentos discretos de funções cognitivas, influência de comorbidades, o conhecimento do nível pré-mórbido de eficiência cognitiva.

No quarto capítulo, de Marucia Patta Bardagi, Altemir José Gonçalves Barbosa, Makilim Nunes Baptista e Marco Antonio Pereira Texeira, as relações familiares recebem destaque, sendo apresentadas suas definições teóricas e descritos os instrumentos brasileiros disponíveis para sua avaliação, bem como estudos que os tenham empregado. Ao levantarem uma possível cisão entre o conhecimento produzido na área de avaliação psicológica e a adoção das ferramentas nela desenvolvidas em pesquisas de intervenção, os autores sugerem que haja uma reflexão crítica sobre o ciclo teoria-avaliação-intervenção a fim de trazer contribuições ainda mais relevantes nos campos teóricos e sua aplicabilidade à prática.

A metacognição, que diz respeito ao conhecimento e cognição sobre o processo cognitivo, é o tema abordado no quinto capítulo. Ao resgatarem historicamente o conceito de metacognição, as autoras Evely Boruchovitchi, Patricia Waltz Schelini e Acácia Ap. Angeli dos Santos trazem importantes considerações sobre as dificuldades e os progressos na sua mensuração, além de apontarem perspectivas de continuidade da sua investigação na área. No decorrer do capítulo ainda são apresentados instrumentos utilizados para avaliar esse construto, tanto no âmbito nacional quanto internacional. Ao final, as autoras destacam a aplicação de estudos a cerca da metacognição, principalmente no que se refere ao fortalecimento da capacidade dessa função desde o início da escolarização formal, como meio de diminuir os índices de fracasso escolar.

O sexto capítulo tem como objetivo explorar as medidas utilizadas para a avaliação do autocontrole, construto este que merece análise sistemática $\mathrm{e}$ detalhada, em função da complexidade do fenômeno. Contudo, tal complexidade acarreta inúmeras dificuldades à sua investigação, como, por exemplo, a falta de instrumental para mensuração. Nesse sentido, os autores Selma de Cássia Martinelli, Fabián Javier 
Marín Rueda e Fermino Fernandes Sisto, ao realizarem uma revisão na literatura, salientam a ausência de instrumentos de avaliação do autocontrole, o que tem dificultado a realização de estudos empíricos. Sendo assim, e com vistas a contribuir com o avanço dessa área de investigação, eles apresentam algumas medidas de investigação do autocontrole no contexto escolar, que vem recebendo destaque em função do aumento da violência no interior das escolas.

Os autores Acácia Aparecida Angeli dos Santos, Soely Aparecida Jorge Polydoro, Marco Antonio Pereira Teixeira e Marucia Patta Bardagi objetivaram, no sétimo capítulo, chamar a atenção para a necessidade de se avaliar e pesquisar as vivências acadêmicas e as experiências de integração de estudantes do Ensino Superior. Para tanto, um panorama da literatura sobre esse tema foi realizado, dando destaque a estudos brasileiros, bem como aos instrumentos psicométricos utilizados. Os autores apontam o baixo volume de pesquisas nacionais realizadas tratando desse construto, reforçando a necessidade de se apresentarem maiores evidências sobre as características do indivíduo no processo de vivência acadêmica.

No oitavo capítulo, de Soely Aparecida Jorge Polydoro, Roberta Gurgel Azzi e Diana Vieira, são encontradas considerações teóricas e metodológicas, ainda que introdutórias, sobre a relação da avaliação da autoeficácia com a Teoria Social Cognitiva, além dos cuidados na construção de escalas de autoeficácia e recomendações práticas para o pesquisador. Ao final, as autoras propõem a colaboração, entre pesquisadores, no desenvolvimento de instrumentos de mensuração desse construto, procurando viabilizar o crescimento de pesquisas no país.

Elaborado por Elisa Medici Pizão Yooshida, Maria Leonor Espinosa Enéas e Tales Vilela Santeiro, o nono capítulo faz uma revisão de pesquisas e aplicações da Escala Diagnóstica Adaptativa Operacionalizada (EDAO), desenvolvida por Ryad Simon, nos anos de 1970. Os autores apresentam o conceito de adaptação proposto por Simon, em uma contextualização teórica, além de destacarem a existência de evidências de validade, originárias de pesquisas que envolveram o construto em diferentes situações e contexto. Assim também, salientam a limitação encontrada para seu uso, em virtude de sua avaliação depender de entrevista clínica para coleta de dados, por vezes impossibilitada de ser realizada por condições ambientais inviáveis.

Katya Oliveira e Evely Boruchovitch apresentam o tema motivação no contexto escolar no décimo capítulo, ao explorarem duas perspectivas teóricas que abrangem o tema, quais sejam, a Teoria da
Autodeterminação e a Teoria das Metas de Realização. A relação entre elas foi verificada em um estudo de validade convergente, por meio de dois instrumentos Escala de Motivação para Aprendizagem (EMA) e Escala de Avaliação da Motivação para Aprender de Alunos Universitários (EMA-U). Os resultados encontrados indicaram que as duas concepções teóricas podem coexistir. Ao final, as autoras sugerem estudos mais aprofundados no tema.

O Teste de Bender, amplamente conhecido, foi estudado no seu novo sistema de correção, o Sistema de Pontuação Gradual, por Adriana Cristina Boulhoça Suehiro, Acácia Aparecida Angeli dos Santos e Ana Paula Porto Noronha, no capítulo onze. As autoras buscaram investigar, em revisão históriaca e descrição de pesquisas, a existência da relação entre a maturidade visomotora medida pelo teste e o desempenho em leitura e escrita. Tal objetivo permitiu verificar que, apesar da importância dos construtos focados, a relação entre eles ainda é pouco explorada tanto no âmbito nacional como no internacional. Apesar disso, o teste tem sido usado como importante fonte de informação auxiliar sobre o desempenho em leitura e escrita, o que amplia as possibilidades investigativas quando dos processos de avaliação psicológica.

O capítulo doze, de autoria de Evely Boruchovitch e Denise Bortoletto, objetivou rever a literatura sobre as estratégias de regulação emocional, ao considerar a importância dessas estratégias, também chamadas de estratégias de coping ou de enfrentamento, essenciais para a compreensão desse processo de regulação. As autoras apresentam a descrição desse construto e os instrumentos existentes para sua mensuração, disponíveis tanto na literatura nacional como internacional. Visto que as estratégias de regulação desempenham papel importante na vida das pessoas, elas destacam o consenso entre os pesquisadores que consideram tal regulação, quando bem-sucedida, pré-requisito para o funcionamento adaptativo do ser humano.

Por fim, o último capítulo foi elaborado por Vera Lucia Marques de Figueiredo, Antonielle Cantarelli Martins, Francielle Cantarelli Martins, Olga Cassal Viedo, Shana Gularte Della Vechia, Tharso de Souza Meyer e William Martins de Oliveira, e teve como finalidade resgatar os testes psicológicos mais utilizados na avaliação de indivíduos surdos usuários da língua de sinais. Os autores destacam a carência, na área da psicologia, em relação ao atendimento e entendimento da comunidade surda, o que acaba se tornando uma limitação para a efetivação de pesquisas com essa população. Da mesma forma, há a dificuldade para o desenvolvimento de instrumentos que possuam 
estudos de validade e fidedignidade, e, principalmente, o estabelecimento de normas apropriadas, viabilizando a produção de medidas mais confiáveis na avaliação de surdos.

O livro resenhado traz informações relevantes para estudantes, professores, pesquisadores e profissionais não só da psicologia, mas todos aqueles que dão especial atenção à área de Avaliação psicológica. Os organizadores trazem valiosa contribuição por apresentarem, acerca do panorama atual da avaliação no país, as temáticas fortemente discutidas e em expansão pelas pesquisas e levantamentos realizados por seus especialistas.

Sobre a autora:

Lariana Paula Pinto é psicóloga, mestranda do Programa de Pós-Graduação Stricto Sensu em Psicologia da Universidade de São Francisco e bolsista pela CAPES. 
